\title{
Use of an educational computer program before genetic counseling for breast cancer susceptibility: Effects on duration and content of counseling sessions
}

Michael J. Green, MD, MS ${ }^{1}$, Susan K. Peterson, PhD, MPH', Maria Wagner Baker, PhD ${ }^{3}$, Lois C. Friedman, $P h D^{4}$, Gregory R. Harper, $M D, P h D^{5}$, Wendy S. Rubinstein, $M D, P h D^{6}$, June A. Peters, $M S^{7}$, and David T. Mauger, PhD

\begin{abstract}
Purpose: Patients seeking genetic testing for inherited breast cancer risk are typically educated by genetic counselors; however, the growing demand for cancer genetic testing will likely exceed the availability of counselors trained in this area. We compared the effectiveness of counseling alone versus counseling preceded by use of a computer-based decision aid among women referred to genetic counseling for a family or personal history of breast cancer. Methods: We developed and evaluated an interactive computer program that educates women about breast cancer, heredity, and genetic testing. Between May 2000 and September 2002, women at six study sites were randomized into either: Counselor Group $(n=105)$, who received standard genetic counseling, or Computer Group ( $n=106$ ), who used the interactive computer program before counseling. Clients and counselors both evaluated the effectiveness of counseling sessions, and counselors completed additional measures for the Computer Group. Counselors also recorded the duration of each session. Results: Baseline characteristics did not differ significantly between groups. Participants and counselors both rated the counseling sessions as highly effective, whether or not the sessions were preceded by computer use. Computer use resulted in significantly shorter counseling sessions among women at low risk for carrying BRCA1/2 mutations. In approximately half of the sessions preceded by clients' computer use, counselors indicated that clients' use of the computer program affected the way they used the time, shifting the focus away from basic education toward personal risk and decision-making. Conclusion: This study shows that the interactive computer program "Breast Cancer Risk and Genetic Testing" is a valuable adjunct to genetic counseling. Its use before counseling can shorten counseling sessions and allow counselors to focus more on the clients' individual risks and specific psychological concerns. As the demand for counseling services increases, a program such as this can play a valuable role in enhancing counseling efficiency. Genet Med 2005:7(4):221-229.
\end{abstract}

Key Words: genetic counseling, breast cancer, decision aids, computer based education, genes BRCA1/2

In the past decade, there has been an unprecedented explosion of genetic discovery, culminating in the complete sequencing of the human genome in April 2003. ${ }^{1}$ Molecular tests now permit evaluation of a person's genetic susceptibility to various cancers, and as more conditions are identified for which genetic testing can be performed, ${ }^{2-4}$ it is inevitable that

\footnotetext{
From ${ }^{1}$ Penn State College of Medicine, Hershey, Pennsylvania; ${ }^{2}$ University of Texas MD Anderson Cancer Center, Houston, Texas; ${ }^{3}$ Penn State Cancer Institute, The Milton S. Hershey Medical Center, Hershey, Pennsylvania; ${ }^{4}$ Baylor College of Medicine, Houston, Texas; ${ }^{5}$ Penn State Cancer Institute, Lehigh Valley Hospital, Allentown, Pennsylvania; ${ }^{6}$ Evanston Northwestern Healthcare, Evanston, Illinois; and the ${ }^{7}$ National Institutes of Health, Department of Health and Human Services, Rockville, Maryland.

Michael J Green, MD, MS, Departments of Humanities and Medicine, Room C1743, Penn State College of Medicine, H134, 500 University Drive, Hershey, PA 17033.

Received: October 21, 2004.

Accepted: January 31, 2005.
}

DOI: 10.1097/01.GIM.0000159905.13125.86 genetic testing will be used more frequently to make predictive, diagnostic, and risk management decisions.5,6 In fact, genetic tests are now marketed directly to physicians and to the public, increasing the frequency of patients' requests for testing from their physicians. ${ }^{9}$ Even so, it is well-documented that primary care physicians' knowledge and comfort levels with genetic information are limited. ${ }^{8-10}$ Without adequate understanding of the strengths and limitations of genetic testing, many patients may undergo genetic testing that is not necessary or informative and may, in fact, be ill advised. ${ }^{11-16}$

Thus, there is a consensus in the genetics community that patients who are considering genetic testing for inherited cancer risk should be educated about risks, benefits, and alternatives before being tested. ${ }^{17}$ This education is typically provided by genetic counselors trained in cancer genetics. However, with approximately 1800 board-certified genetic counselors in the United States, ${ }^{18}$ and fewer than 400 genetic counselors who 
list cancer as their specialty, ${ }^{19}$ the growing demand for cancer genetic testing will likely exceed the availability of counselors trained in this area. ${ }^{20-22}$ Consequently, alternative or adjunct educational resources are necessary to help meet the educational needs of individuals who seek cancer genetic counseling and to enhance the genetic counseling process.

The need for accurate information about genetic aspects of breast cancer is particularly pressing. Breast cancer is the most commonly occurring nonskin cancer among women, and it is estimated that 215,000 women will develop invasive breast cancer and more than 40,000 will die from it in 2004. ${ }^{23} \mathrm{Ap}$ proximately $7 \%$ of breast cancer cases are associated with an autosomal dominant pattern of inheritance, ${ }^{24}$ and of these, $84 \%$ are associated with mutations in the breast cancer-susceptibility genes $B R C A 1$ and $B R C A 2^{25}$ for which genetic testing is clinically available.

To address this growing need, we developed an interactive computer-based decision aid ("Breast Cancer Risk and Genetic Testing") to educate women considering genetic testing for breast cancer susceptibility. ${ }^{26,27}$ The program is a multimedia, interactive decision aid designed to help people make informed decisions about genetic testing for breast cancer susceptibility and was developed by an interdisciplinary team of educators, physicians, genetic counselors, and scientists. It is organized into three sections: Section 1 provides a brief overview of breast cancer, Section 2 discusses breast cancer genetics, and Section 3 addresses gene testing for breast cancer. In each section, a series of questions and answers guide the user through the content material. The general structure is for a simulated "patient" to ask a question (for example, "what is breast cancer?") and then for an "expert" narrator to provide an answer. The questions are asked by various women of diverse backgrounds, while the answers are given by one female expert. In our early experience piloting the CD-ROM with a diverse group of women (unreported data), we observed that each user would navigate through the program differently, focusing on her particular areas of interest.

In an initial clinical trial, we found that the program was well-accepted by genetic counselors and their clients, ${ }^{28}$ and its use increased clients' knowledge about breast cancer genetics and decreased their intention to undergo testing. ${ }^{29}$

Subsequently, we revised and updated the computer program and conducted a larger, randomized, multicenter trial among women referred for genetic counseling due to family or personal histories of breast cancer. ${ }^{30}$ In this article, we report findings from one aspect of that study that compared the effectiveness of counseling alone with counseling preceded by computer use. The study questions were as follows: (1) From the clients' perspective, were counseling sessions supplemented by a computer program more effective than standard counseling sessions? (2) From the genetic counselors' perspective, were counseling sessions supplemented by computer more effective than standard counseling sessions? (3) Compared to standard genetic counseling, was counseling supplemented by computer: (a) more efficient, (b) shorter in duration, and (c) different with regard to content? Answers to these questions are important, as they may shed light on the potential applicability and implementation of this program in other settings and with other health care providers.

\section{MATERIALS AND METHODS}

\section{Participants}

Between May 2000 and September 2002, women who had been referred to a genetic counselor for evaluation of breast cancer risk were recruited to participate in a trial to compare the effectiveness of computer-based counseling with face-toface genetic counseling. There were six study sites in this trial (Penn State College of Medicine, Hershey PA; Lehigh Valley Hospital and Health Network, Allentown, PA; The University of Texas MD Anderson Cancer Center, Houston, TX; Baylor College of Medicine, Houston, TX; University of Pittsburgh Medical Center, Pittsburgh, PA; and Evanston Northwestern Health Care, Evanston, IL.). The protocol received Institutional Review Board (IRB) approval at each of the participating sites and was monitored by each local IRB. Women were eligible to participate in this study if they were 18 years of age or older; could read, write, and speak English; scheduled a genetic counseling appointment to evaluate personal and/or family histories of breast cancer; and were able to give informed consent. Women who previously underwent genetic counseling or testing for inherited breast cancer susceptibility were excluded.

\section{Design and procedures}

This was a randomized trial comparing the effectiveness of genetic counseling alone with counseling supplemented by computer use from the perspectives of both clients and counselors. Participants (clients) were randomized into one of two groups before the actual date of their genetic counseling appointment: (1) Counselor Group $(n=105)$, who received standard genetic education and risk assessment by genetic counseling professionals, and (2) Computer Group $(n=106)$, who used the interactive computer program before their genetic counseling sessions. To ensure that equal numbers of high- and low-risk women were included in both arms of the study, each study site maintained two separate randomization lists: one for women at high risk of carrying a BRCA1/2 mutation $(\geq 10 \%)$ and one for women at low risk $(<10 \%)$ as calculated using the BRCAPRO model. ${ }^{31-34}$

Before their counseling appointments, participants provided written informed consent and completed baseline questionnaires. Participants who were assigned to the Counselor Group proceeded directly from baseline data collection to their genetic counseling appointments. Participants assigned to the Computer Group were directed by project staff to an area where they could use the computer program. After completing the program and some questions, these participants proceeded to their genetic counseling sessions. Immediately after counseling, participants in both groups completed identical postintervention questionnaires. Counselors also completed postsession questionnaires at that time, including items about the impact of computer use on the counseling sessions. For this 
reason, the counselors were not blinded as to clients' study group assignments.

\section{Interventions}

\section{Computer-based educational intervention}

The computer program ("Breast Cancer Risk and Genetic Testing") is an interactive, multimedia, CD-ROM decision aid designed to educate women about breast cancer, heredity, and positive and negative aspects of genetic testing. It has been described in detail elsewhere ${ }^{27}$ and has received positive reviews in the medical literature. ${ }^{35-39}$ The program's main purpose is to help women make informed decisions about BRCA1/2 genetic testing and includes information about breast cancer risk, the role of heredity in the development of breast and ovarian cancers, and the benefits and limitations of genetic testing for $B R C A 1$ and $B R C A 2$ mutations. It is easy to use, requires no prior experience with computers, and was designed for women of different ages and educational levels. Because it is self-paced and user-driven, each user determines the sequence of accessing various sections, as well as the amount of time spent on each section. In this study, participants spent on average 45 to 60 minutes using the program.

\section{Genetic counseling}

Genetic counseling was provided by 12 certified genetic counselors and one advanced practice nurse with specialty training in cancer genetics, collectively referred to as "counselors." Investigators and counselors agreed upon a set of topics to be discussed during the counseling sessions based on accepted guidelines ${ }^{40}$ and these topics corresponded to the computer program's content. Unlike the computer program, genetic counseling sessions also included individualized risk estimates of the likelihood of carrying a gene mutation, and psychosocial support to address emotional concerns related to breast cancer risk and genetic testing.

\section{Measures}

At baseline, participants were asked about demographic characteristics and experience with computers. Medical literacy was assessed using the Rapid Estimate of Adult Literacy in Medicine (REALM), a reliable and valid measure to provide an estimate of a person's reading ability with regard to medical terminology. ${ }^{41}$ Personal and family cancer history information was collected before the counseling appointment, and counselors used the BRCAPRO model ${ }^{31-34}$ to calculate each participant's estimated risk of carrying a $B R C A 1$ or $B R C A 2$ germ-line mutation. After the counseling sessions, the following outcome measures were administered to both groups.

\section{Effectiveness of session}

The perceived overall effectiveness of the counseling sessions was assessed with a single question completed by both research participants and counselors: "Overall, how effective was this session with the (genetic counselor/client)?" Response options ranged from 1 (Not at all effective) to 7 (Extremely effective). Additionally, participants and counselors were asked to rate 12 attributes of the counseling session, including the following: clients' willingness to share worries and fears; their understanding of breast cancer, heredity and genetic testing; their preparedness for making a decision about testing; the quality of questions asked; the level of rapport with the counselor; and the extent to which emotional and informational needs were met. Response options ranged from 1 (Poor) to 4 (Excellent).

\section{Duration of counseling sessions}

The amount of time each participant spent in the counseling session was recorded by the genetic counselor.

\section{Impact of computer use on the counseling session}

Counselors were asked to assess the impact of the computer program on the genetic counseling sessions by answering four questions: (1) Did the client's use of the CD-ROM permit you to skip over material you typically present? (2) Did it help you to use your time more efficiently? (3) Did it alter the content of your discussion? (4) Did it affect the way you used your time? Response options were "Yes," "No," and "Not sure," followed by space for explanatory comments.

\section{Data Analysis}

Descriptive statistics were computed for all variables. Group differences in continuous outcomes such as age, REALM score, and length and quantitative effectiveness of counseling sessions were assessed by $t$ tests. Group differences in categorical and ordinal outcomes such as race, estimated risk of mutation, and Likert scale responses were assessed by Chi-square test. Fourand five-point Likert scale responses were analyzed as ordinal outcomes. These responses were collapsed into a smaller number of categories when one or more levels had fewer than five responses. All analyses were performed using the SAS statistical software system version 8.1 (SAS Institute, Cary, NC).

The open-ended responses were analyzed using qualitative methods to identify emergent themes related to the research questions. ${ }^{42}$ The investigators created a coding scheme by reviewing responses and identifying common themes. Using an iterative process, two investigators sorted responses into categories, reducing the categories to a manageable number. Characteristic responses were identified and quotations were included verbatim, excluding names to protect confidentiality. Themes and findings from the analysis also underwent independent review by other study investigators.

\section{RESULTS}

\section{Participant characteristics}

Of 432 eligible women who were invited to participate in this study, 288 agreed, 77 did not keep appointments, and 211 were randomly assigned to either the Computer Group or the Counselor Group (Fig. 1). Baseline characteristics did not differ significantly between the Computer and Counselor Groups (Table 1). Participants' mean age was 44 years, $74 \%$ were $<50$ 


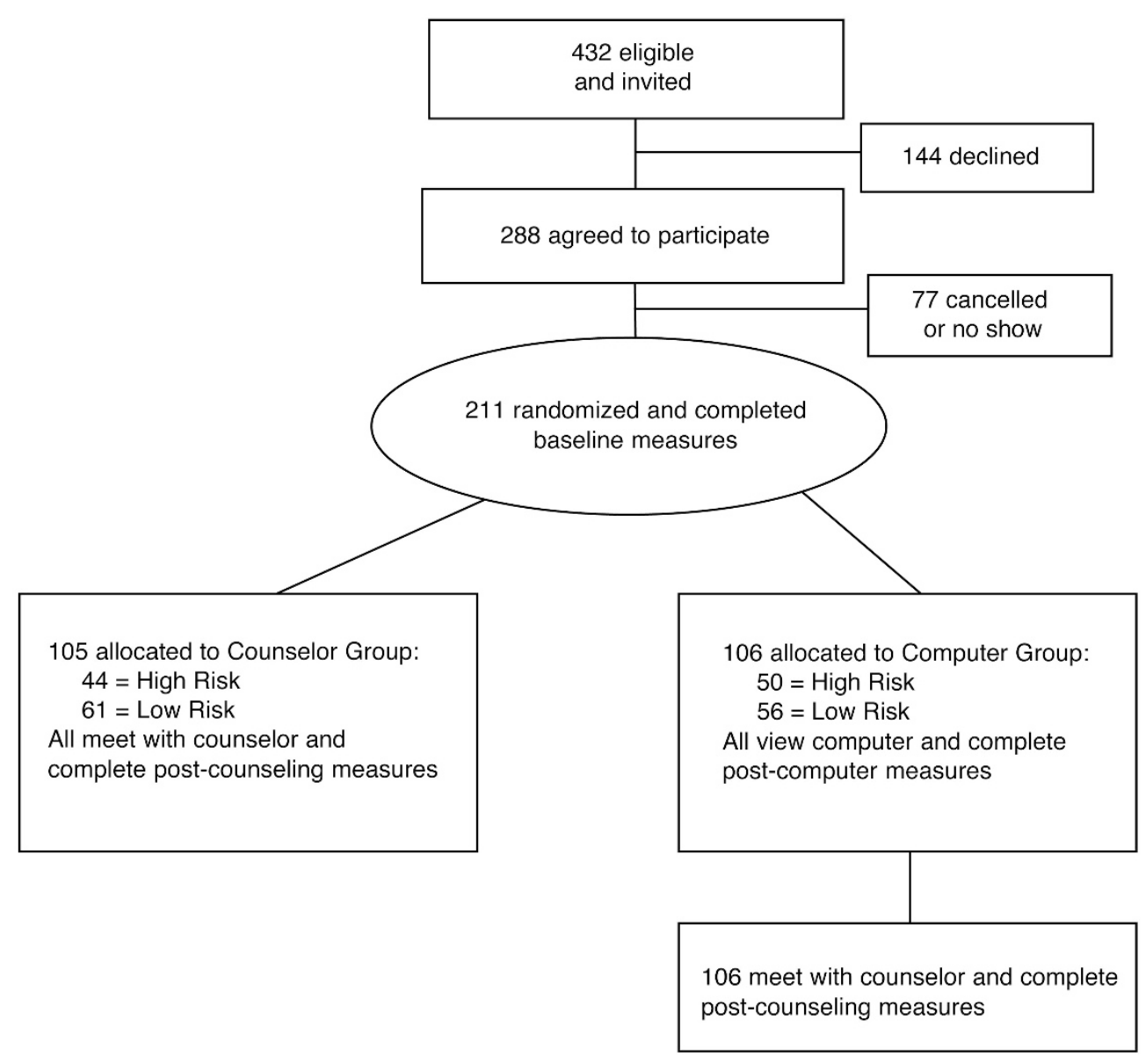

Fig. 1. Design of the study and subject participation.

years old, $56 \%$ had completed college or beyond, and $93 \%$ were white. Thirty-nine percent reported being "very confident" with their computer skills, $64 \%$ reported using a computer "often" at home or at work, and $42 \%$ reported having heard or read "a fair amount" or "a lot" about genetic testing. Mean REALM scores indicated a high level of familiarity with medical terms (65 on a scale from 1 to 66). Based on BRCAPRO estimates, $55 \%$ of participants had less than a $10 \%$ chance of carrying a mutation (low risk) and $45 \%$ of participants had a $10 \%$ or greater chance (high risk). Low and high risk individuals were similar with respect to most baseline characteristics, but high-risk individuals were younger ( 42 vs. 47 years; $P<$ 0.003 ) and more familiar with genetic testing (50\% vs. $36 \%$ reported having read or heard "a fair amount or a lot" about genetic testing; $P=0.04$ ).

\section{Effectiveness of the counseling session}

Participants and counselors both rated the counseling sessions as highly effective overall, whether or not the sessions were preceded by computer use (Table 2). The mean effectiveness rating by participants (on a scale of 1-7) was 6.6 in both the Counselor and Computer Groups. Counselors also rated the sessions as highly effective, although less so than the par- ticipants $(P<0.001)$. Participants' ratings of the effectiveness of the session did not differ based on risk status.

In addition to an overall effectiveness rating, participants and counselors also rated 12 specific attributes of the counseling sessions. On 11 of 12 items, participants once again rated the effectiveness of the sessions significantly higher $(P<$ 0.0001) compared with the counselors (Table 3). Participants' responses did not differ by group status or by risk status. Likewise, counselors' responses for 11 of 12 items did not differ by participants' group status; however, they indicated that clients in the Computer Group had a better understanding of heredity than those in the Counselor Group $(P=0.03)$.

\section{Duration of counseling sessions}

Overall, computer program use resulted in shorter face-toface counseling sessions (90 minutes in the Counseling Group vs. 82 minutes in the Computer Group; $P=0.03$ ). When analyzed by risk status, this reduction in the duration of counseling sessions was significant among women at low risk for carrying $B R C A 1 / 2$ mutations (89 minutes in Counselor Group and 77 minutes in the Computer Group; $P=0.027$ ), but not among those at high risk (91 vs. 86 minutes; $P=0.39$ ). 
Table 1

Baseline characteristics of study participants by group assignment

\begin{tabular}{|c|c|c|c|}
\hline Characteristic & $\begin{array}{c}\text { Counselor group } \\
n=105\end{array}$ & $\begin{array}{l}\text { Computer group } \\
n=106\end{array}$ & $P$ value \\
\hline Mean age, $y$ (range) & $44(24-71)$ & $45(23-77)$ & 0.33 \\
\hline Race/ethnicity, White, n (\%) & $95(90)$ & $100(95)$ & 0.28 \\
\hline \multicolumn{4}{|l|}{ Education } \\
\hline$\geq$ College Grad n (\%) & $53(50)$ & $65(62)$ & 0.095 \\
\hline \multicolumn{4}{|l|}{ Religion, n (\%) } \\
\hline Catholic & $27(26)$ & $38(37)$ & \\
\hline Protestant or other Christian & $52(50)$ & $45(44)$ & \\
\hline Jewish & $7(7)$ & $7(7)$ & \\
\hline Other or None & $17(17)$ & $13(13)$ & \\
\hline "Very strong" religious or spiritual faith, n (\%) & $53(50)$ & $47(44)$ & 0.37 \\
\hline \multicolumn{4}{|l|}{ Computer use at work, n (\%) } \\
\hline Often or sometimes & $71(72)$ & $83(82)$ & 0.4 \\
\hline \multicolumn{4}{|l|}{ Computer use to manage personal affairs, $\mathrm{n}(\%)$} \\
\hline Often or sometimes & $63(61)$ & $68(65)$ & 0.12 \\
\hline Very confident with computer skills, n (\%) & $39(37)$ & $44(42)$ & 0.78 \\
\hline \multicolumn{4}{|c|}{ How much have you read or heard about genetic testing? n (\%) } \\
\hline Fair amount or a lot & $44(42)$ & $45(42)$ & 0.98 \\
\hline Mean REALM health literacy score (range 0-66) & 65 & 65 & $>0.99$ \\
\hline Calculated risk of carrying a $B R C A 1 / 2$ mutation & & & 0.4 \\
\hline High risk ( $\geq 10 \%$ chance), $\mathrm{n}(\%)$ & $44(42)$ & $50(47)$ & \\
\hline Low risk ( $<10 \%$ chance), $\mathrm{n}(\%)$ & $61(58)$ & $56(53)$ & \\
\hline Personal history of breast cancer, $\mathrm{n}(\%)$ & $29(28)$ & $35(33)$ & 0.37 \\
\hline
\end{tabular}

Table 2

Assessment of effectiveness of counseling session by clients and counselors ( $1=$ not at all effective, $7=$ extremely effective $)$

\begin{tabular}{lcc}
\hline Overall, how effective was this session? & Counselor group & Computer group \\
\hline Clients' assessment & 6.6 & 6.6 \\
Counselors' assessment & 5.8 & 5.9 \\
$P$ value (comparing mean clients' with mean counselors' scores) & $<0.001$ & $<0.001$ \\
\hline
\end{tabular}

\section{Impact of the computer program on provision of counseling}

In approximately half of the counseling sessions involving the Computer Group, counselors reported that clients' computer use permitted them to alter some aspect of their typical counseling practices. Specifically, it permitted counselors to do the following: alter the content of discussions in $53 \%$ of sessions; change the way they used their time in $50 \%$ of sessions; use their time more efficiently in $44 \%$ of sessions; and skip material they typically present in 33\% of sessions (Fig. 2). These findings were similar for high- and low-risk women. Counselors' comments (see following sections) explained how the computer program affected the counseling sessions.
Impact of the computer program on content of discussion during counseling session

Thirty two percent of the counselors indicated that they did not alter the content of their counseling discussions with Computer Group participants. However, most counselors (53\%) reported that they did alter the content of these discussions, and described two main ways in which they did so. First, participants' use of the computer before the session allowed counselors to shift the focus of discussions away from explanations of basic genetic concepts, and toward the specific concerns of individual clients. For example: "spent more time focusing on (the) plan, not on education"; "(spent) less time talking about 
Table 3

Clients' and counselors' ratings of specific attributes of counseling session (mean scores) ${ }^{a}$

\begin{tabular}{|c|c|c|c|c|c|c|}
\hline & \multicolumn{3}{|c|}{ Clients' perception } & \multicolumn{3}{|c|}{ Counselors' perception $^{d}$} \\
\hline & $\begin{array}{l}\text { Counselor group } \\
\quad(N=102)\end{array}$ & $\begin{array}{l}\text { Computer group } \\
\qquad(N=104)\end{array}$ & $P$ value ${ }^{b}$ & $\begin{array}{l}\text { Counselor group } \\
\qquad(N=101)\end{array}$ & $\begin{array}{l}\text { Computer group } \\
\quad(N=103)\end{array}$ & $P$ value ${ }^{c}$ \\
\hline Client's willingness to share worries and fears & 3.6 & 3.6 & 0.85 & 3.3 & 3.2 & 0.15 \\
\hline Client's understanding of breast cancer & 3.4 & 3.4 & 0.89 & 3.0 & 3.0 & 0.62 \\
\hline Client's understanding of heredity & 3.4 & 3.3 & 0.42 & 2.7 & 2.9 & 0.03 \\
\hline Client's understanding of the pros and cons of genetic testing & 3.5 & 3.5 & 0.90 & 2.9 & 3.1 & 0.07 \\
\hline Client's preparedness for making a decision about genetic testing & 3.4 & 3.4 & 0.80 & 2.9 & 3.0 & 0.82 \\
\hline The quality of the questions that client asked & 3.1 & 3.2 & 0.27 & 3.3 & 3.3 & 0.81 \\
\hline The level of rapport established with the genetic counselor & 3.7 & 3.6 & 0.52 & 3.2 & 3.2 & 0.76 \\
\hline $\begin{array}{l}\text { How well the genetic counselor was able to meet client's need for } \\
\text { factual information }\end{array}$ & 3.8 & 3.8 & 0.96 & 3.3 & 3.3 & 0.73 \\
\hline The extent to which client's emotional concerns were addressed & 3.5 & 3.5 & 0.92 & 3.0 & 3.0 & 0.91 \\
\hline $\begin{array}{l}\text { How well the genetic counselor was able to ascertain what was } \\
\text { most important to client }\end{array}$ & 3.6 & 3.7 & 0.72 & 3.2 & 3.3 & 0.67 \\
\hline $\begin{array}{l}\text { How well the genetic counselor was able to tailor the discussion } \\
\text { to client's specific concerns }\end{array}$ & 3.8 & 3.7 & 0.29 & 3.3 & 3.3 & 0.77 \\
\hline Level of personal satisfaction with this session & 3.8 & 3.8 & 0.81 & 3.1 & 3.2 & 0.09 \\
\hline
\end{tabular}

${ }^{a}$ Excellent $=4$, Good $=3$, Fair $=2$, Poor $=1$, N/A (excluded from analysis).

${ }^{b}$ Difference between clients' mean assessment for Counselor Group vs. Computer Group.

${ }^{c}$ Difference between counselors' mean assessment for Counselor Group vs. Computer Group.

${ }^{d}$ Clients rated every item significantly higher than did counselors in both groups $(P<0.05)$ except there was no difference for the item "quality of the questions that client asked."

Did the client's use of the CD-

ROM permit you to...

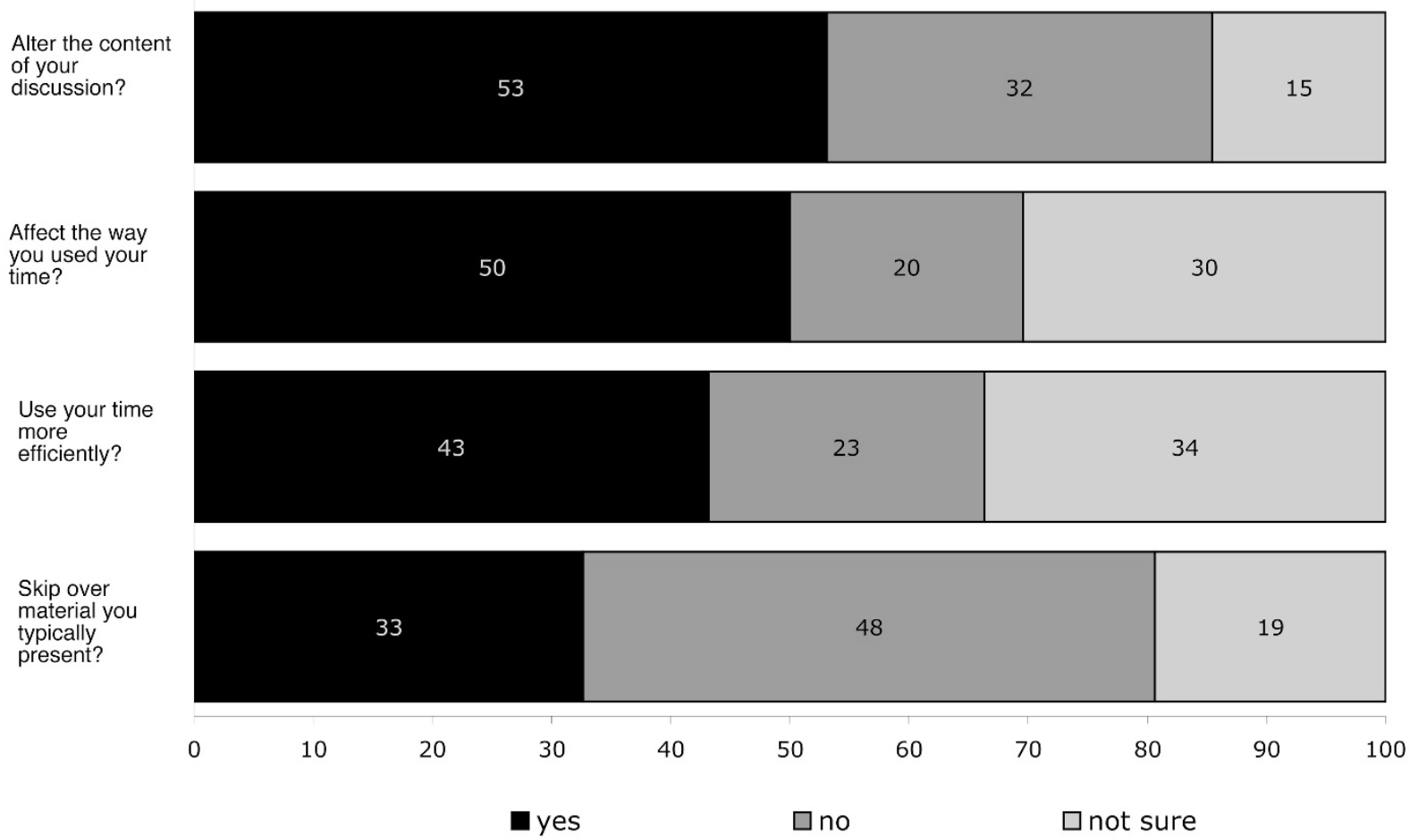

Fig. 2. Impact of computer use on the counseling session. Percent of counselors indicating "yes," "no," and "not sure." 
chromosomes, genes, cancer risks, BRCA1/2"; and "allowed more time to address her specific health concerns." Second, counselors commented that the computer program raised clients' awareness of certain issues, prompting counselors to address questions stimulated by the program: "patient asked questions about insurance discrimination based on what she saw in computer program"; and "patient formulated questions based on information in CD-ROM."

\section{Impact of the computer program on use of time during counseling session}

Counselors indicated that they altered the way they used their time in $50 \%$ of the sessions preceded by computer use. In particular, counselors indicated that use of the program by these clients allowed them to redirect the emphasis of the sessions to specific issues identified by clients. For example: "more time... spent discussing ambivalence with regard to pursuing genetic testing"; "more time on clinical issues and medical surveillance..."; "more time spent on discussion of state and federal laws"; "moved into psychological issues more quickly than usual"; and "more time was spent on the implications of genetic testing for her and for her family." For about $80 \%$ of the clients in the Computer Group, use of the computer program also shortened the amount of time needed for faceto-face counseling.

Counselors indicated that they did not alter the way they used their time in about $20 \%$ of Computer Group sessions. A common explanation was that counselors felt an obligation to review all topics they typically reviewed, regardless of the clients' baseline knowledge.

\section{Impact of the computer program on efficiency of the counseling session}

Counselors reported that the computer program helped them use their time more efficiently in $43 \%$ of sessions and characterized this efficiency in three ways: (1) shifted the focus of discussions to the participants' specific concerns, (2) reinforced concepts that were already presented by the computer, and (3) spent less time providing basic information about genetics.

For example, a shift in focus to clients' specific concerns was illustrated by comments such as the following: "more focused discussion on client's family history and more brief explanation of genetics"; "more time to address client's concerns for ovarian cancer risks"; and "able to address the psychosocial concerns since she had a good understanding of the factual info."

Counselors also reported that sessions were more efficient because many concepts already had been introduced by the computer program: "I believe we went through the information more efficiently because patient had seen the CD"; "it helped that the patient was already introduced to some basic concepts"; and "I think it helps that the patient had already heard the information once."

Finally, counselors reported that sessions were more efficient because they did not need to spend as much time provid- ing basic information: "spent less time on the background information"; "minimized the need for lengthy discussion about genetics"; "some things could be skipped"; and "was able to go through education more quickly."

Counselors indicated that the computer program did not help them use their time more efficiently in $23 \%$ of sessions, and they were not sure whether the program impacted efficiency in $34 \%$ of sessions. One theme that emerged in regard to this response was that involvement in this research study sometimes increased the overall amount of time that counselors needed to be available to clients compared to their standard sessions, due to the added steps and responsibilities required by the study protocol. For example: "It shortened the face-toface time, but lengthened the amount of time I needed to be available to the patient"; [efficiency was not improved] "because of the waiting between scheduled time and actual face time."

\section{Impact of the computer program on the type of information presented during the session}

Counselors reported that they skipped information that they typically presented in $33 \%$ of sessions preceded by computer use. The computer program seemed to influence the amount of information that counselors presented about genetics and heredity, as illustrated by the following comments: "allowed me to use less detail in my descriptions"; "allowed me to spend less time explaining BRCA1/2"; "allowed me to bypass in-depth discussion of modes of inheritance"; "abbreviated discussion of genes, heredity, AD inheritance"; and "I was able to skip over a lot of the information on basic genetics."

\section{DISCUSSION}

Genetic counseling for cancer predisposition is a complex and labor-intensive endeavor, involving provision of information, evaluation and discussion of individual risk factors, and counseling about psychosocial concerns. ${ }^{5,43,44}$ As the demand for cancer genetic counseling increases in response to the rising availability of genetic testing, it will become more important to provide education and counseling in an efficient and effective manner.

The present study demonstrates that an interactive computer program can improve counseling efficiency by shortening the duration of sessions while enabling the counselors to focus on the clients' individual concerns. Because the computer program is effective at providing basic information, it enables counselors to spend their time addressing other important aspects of the counseling process ${ }^{44}$ such as assessing individual risk, providing psychosocial support, and aiding decision-making.

It is encouraging to note that from the clients' point of view, the genetic counselors in this study did their job exceedingly well, and this perception was consistent across intervention groups. Participants rated the counseling sessions very highly overall, as well as on specific attributes such as the following: willingness to share worries and fears; understanding of can- 


\section{Green et al.}

cer, heredity, and the pros/cons of genetic testing; preparedness for making a decision; the extent to which emotional and factual concerns were addressed; and rapport and satisfaction with the counselors and the counseling.

Although counselors also regarded the counseling sessions as largely effective, it is interesting to note that the participants consistently rated the sessions higher than did the counselors. One possible explanation for this finding is that clients inflated their ratings of the counselors by providing socially desirable responses rather than expressing their true feelings. ${ }^{45}$ Another possible explanation is that the responses may reflect a difference in expectations. That is, participants may have been pleasantly surprised by how much they had learned, but counselors may have wished they had accomplished more during the session and thus were comparatively less satisfied.

We had hypothesized that, compared with standard counseling, the use of our computer program before counseling would result in significantly higher effectiveness ratings from the perspectives of both clients and counselors. However, because the effectiveness ratings of counseling sessions were uniformly high without computer use, the addition of the program did not significantly raise scores. Nevertheless, the computer program was effective in several specific ways. According to the counselors, clients' use of the computer permitted tailoring of the content of many discussions and thereby increased counseling efficiency in the majority of sessions. Counselors particularly noted that clients' computer use resulted in shorter counseling sessions, more focused education, and the opportunity to better address the participants' individual concerns.

Although use of the computer program shortened face-toface time with the counselors among low-risk women, it is important to note that its use increased the overall time of study visits. This is not surprising, because using the computer program as part of a study protocol required an additional hour of educational activities. Whether more time would be necessary outside a study is not known. Even so, if counselors are to increase their capacity in the clinic, it will be necessary for them to be able to predict in advance which clients would require less time. Future research can address whether using the program at home in advance of the counseling visits would be beneficial to clients and would result in shorter counseling sessions.

A couple findings warrant further comment. Counselors indicated that the computer program did not lead to more efficient use of their time in $23 \%$ of sessions, and were not sure of its impact on efficiency in $34 \%$ of sessions. Because participation in a research trial involves extra time for scheduling and data collection, it is possible that these responses reflected the burden imposed by research-related tasks. This is an important methodological issue to address when designing future genetic counseling intervention studies.

Similarly, in $48 \%$ of the sessions, counselors said the computer program did not permit them to skip over material they typically present. These results are largely explained by the responses of a single genetic counselor, who indicated 29 times that although the CD-ROM was useful, (s)he did not feel comfortable altering his/her normal pattern of interaction with clients just because they were enrolled in a research study. It would therefore be interesting to know whether the computer program would have a different impact outside the research setting.

\section{Limitations}

This study has a number of limitations. The overall effectiveness of the counseling session was assessed with a single question answered by both participants and counselors. Such a global effectiveness score may lack sensitivity to detect subtle differences in counseling effectiveness. Consequently, the results may reflect a limitation of the tool rather than the computer program. Second, because this was not a blinded study, counselors knew which participants had and had not used the computer program. As such, counselors' responses may have been biased.

Third, our results may not be applicable to other populations. Of 432 eligible women, about half participated in the study, and we have no information about those who declined. The women who enrolled in the study were predominantly white, relatively young (mean age 44 years), well educated, and comfortable with using computers. Whether these were "typical" clients seeking genetic counseling for breast cancer susceptibility is not known, and the utility of the computer program for a more diverse population remains to be shown.

Despite these limitations, this study shows that our interactive computer program "Breast Cancer Risk and Genetic Testing" is a valuable adjunct to genetic counseling. Its use before counseling not only shortens some counseling sessions, but more importantly, frees counselors to spend their time discussing the clients' individual risks and specific psychological concerns. As the demand for counseling services increases, a program such as this can play a valuable role in enhancing counseling efficiency, particularly with those at low risk for carrying a gene mutation. Ultimately, the program may have its greatest impact as an educational resource for primary care providers, who are situated to decide which of their patients can benefit most from the services of a genetic counselor, and which may be adequately served through alternative educational measures. As a group currently unprepared to meet the needs of patients seeking information about inherited susceptibility syndromes, ${ }^{10}$ primary care providers can benefit greatly from innovative educational resources.

\section{ACKNOWLEDGMENTS}

This research was supported by grant numbers R03CA70638 and R01CA84770 from the National Cancer Institute and The National Human Genome Research Institute, National Institutes of Health, Bethesda, MD (Principal Investigator: Michael Green, MD, MS). The authors performed the design and conduct of the study; collection, management, analysis, and interpretation of the data; and preparation, review, and approval of the manuscript without the sponsor's participation. The distributor of the program had no role in the 
study design or implementation. Some of the results from this study were reported at the following: the 27th annual meeting of the Society for General Internal Medicine (May 14, 2004, Chicago, IL); the 7th annual meeting of NCHPEG/GROW (January 29, 2004, Bethesda, MD); and the 53rd Annual Meeting of the American Society of Human Genetics (November 6, 2003, Los Angeles, CA). We would like to acknowledge Joanne Caulfield, Dr. Andrew Baum, Dr. Norm Fost, and the genetic counselors who provided guidance and feedback on the development of the study questionnaire. Copies of the computer program, "Breast Cancer Risk and Genetic Testing," are available through Medical Audio Visual Communications, Inc. Suite 240, 2315 Whirlpool Street, Niagara Falls, New York, 14305; Phone: 1-800-757-4868. E-mail: dwc@mavc.com. http://www.mavc.com ( $\$ 49$ for individuals and $\$ 99$ for institutions).

\section{References}

1. International Consortium Completes Human Genome Project: All goals achieved; New vision for genome research unveiled, 2004. National Human Genome Research Institute, National Institutes of Health, Department of Health and Human Services, and Office of Science U.S. Department of Energy; 2003.

2. Eng C, Hampel H, de la Chapelle A. Genetic testing for cancer predisposition. Annu Rev Med 2001;52:371-400.

3. Collins F. Shattuck lecture: Medical and societal consequences of the Human Genome Project. N Engl J Med 1999;341:28-37.

4. Petersen GM. Genetic testing. Hematol Oncol Clin North Am 2000;14:939-52.

5. Biesecker BB. Future directions in genetic counseling: Practical and ethical considerations. Kennedy Institute of Ethics Journal 1998;8:145-160.

6. Schwartz MD, Lerman C, Brogan B, Peshkin BN, Halbert CH, DeMarco T et al. Impact of BRCA1/BRCA2 counseling and testing on newly diagnosed breast cancer patients. J Clin Oncol 2004;22:1823-1829.

7. Gollust SE, Hull SC, Wilfond BS. Limitations of direct-to-consumer advertising for clinical genetic testing. JAMA 2002;288:1762-1767.

8. Freedman AN, Wideroff L, Olson L et al. US physicians' attitudes toward genetic testing for cancer susceptibility. Am J Med Genet 2003;120A:63-71.

9. Friedman LC, Cooper HP, Webb JA, Weinberg AD, Plon SE. Primary care physicians' attitudes and practices regarding cancer genetics: a comparison of 2001 with 1996 survey results. J Cancer Educ 2003;18:91-94.

10. Greendale K, Pyeritz RE. Empowering primary care health professionals in medical genetics: how soon? How fast? How far? Am J Med Genet 2001;106:223-32.

11. Burke W, Emery J. Genetics education for primary-care providers. Nat Rev Genet 2002;3:561-566.

12. Geller G, Tambor WS, Chase GA, Hofman KJ, Faden RR, Holtzman NA. Incorporation of genetics in primary care practice-will physicians do the counseling and will they be directive? Arch Family Med 1993;2:1119-1125.

13. Hofman KJ, Tambor ES, Chase GA, Geller G, Faden RR, Holtzman NA. Physicians' knowledge of genetics and genetic tests. Academic Med 1993;68:625-632.

14. Elsas LJ II, Trepanier A. Cancer genetics in primary care. When is genetic screening an option and when is it the standard of care? Postgraduate Medicine 2000;107:191194,197-200,205-208.

15. Emery J, Lucassen A, Murphy M. Common hereditary cancers and implications for primary care. Lancet 2001;358:56-63.

16. Emery J, Hayflick S. The challenge of integrating genetic medicine into primary care. BMJ 2001;322:1027-1030.

17. Geller G, Botkin JR, Green MJ, Press N, Biesecker BB, Wilfond B et al. Genetic testing for susceptibility to adult-onset cancer. The process and content of informed consent. JAMA 1997;277:1467-1474.

18. American Board of Genetic Counselors. 2004. Available at: http://www.abgc.net/ genetics/abgc/about/intro.shtml. Accessed January 31, 2005.
19. National Society of Genetic Counselors Familial Cancer Risk Counseling Special Interest Group Directory; 2003.

20. Cooksey JA. The genetic counselor workforce. Chicago: Illinois Center for Health Workforce Studies; 2000.

21. Andrews LB, Fullarton JE, Holtzman NA, Motulsky AG. Assessing genetic risks: Implications for health and social policy. Washington, DC: National Academy Press; 1994.

22. Holtzman NA, Watson MS. Promoting safe and effective genetic testing in the United States: Final report of the Task Force on Genetic Testing. Baltimore: Johns Hopkins University Press; 1998.

23. Jemal A, Tiwari RC, Murray T, Ghafoor A, Samuels A, Ward E et al. Cancer statistics, 2004. CA Cancer J Clin 2004;54:8-29.

24. Claus EB, Schildkraut JM, Thompson WD, Risch NJ. The genetic attributable risk of breast and ovarian cancer. Cancer 1996;77:2318-2324.

25. Ford D, Easton DF, Stratton $\mathrm{M}$ et al. Genetic heterogeneity and penetrance analysis of the BRCA1 and BRCA2 genes in breast cancer families. The Breast Cancer Linkage Consortium. Am J Hum Genet 1998;62:676-89.

26. Green MJ, Fost N. CD-ROM: Counseling by computer: Breast cancer risk and genetic testing. Madison, WI: Wisconsin Alumni Research Foundation; 1998.

27. Green MJ, Fost N. An interactive computer program for educating and counseling patients about genetic susceptibility to breast cancer. J Cancer Educ 1997;12:204208.

28. Green MJ, McInerney AM, Biesecker BB, Fost N. Education about genetic testing for breast cancer susceptibility: Patient preferences for a computer program or genetic counselor. Am J Med Genet 2001;103:24-31.

29. Green MJ, Biesecker BB, McInerney AM, Mauger D, Fost N. An interactive computer program can effectively educate patients about genetic testing for breast cancer susceptibility. Am J Med Genet 2001;103:16-23.

30. Green MJ, Peterson SK, Baker MW, Harper GR, Friedman LC, Rubinstein WS et al. Effect of a computer-based decision aid on knowledge, perceptions, and intentions about genetic testing for breast cancer susceptibility: a randomized controlled trial. JAMA 2004;292:442-452.

31. Berry DA, Parmigiani G, Sanchez J, Schildkraut J, Winer E. Probability of carrying a mutation of breast-ovarian cancer gene BRCA1 based on family history. J Natl Cancer Inst 1997;89:227-238.

32. Parmigiani G, Berry D, Aguilar O. Determining carrier probabilities for breast cancer-susceptibility genes BRCA1 and BRCA2. Am J Hum Genet 1998;62:145-158.

33. Euhus DM, Smith KC, Robinson L, Stucky A, Olopade OI, Cummings S et al. Pretest prediction of BRCA1 or BRCA2 mutation by risk counselors and the computer model BRCAPRO. J Natl Cancer Inst 2002;94:844-851.

34. Berry DA, Iversen ES Jr, Gudbjartsson DF, Hiller EH, Garber JE, Peshkin BN et al. BRCAPRO validation, sensitivity of genetic testing of BRCA1/BRCA2, and prevalence of other breast cancer susceptibility genes. J Clin Oncol 2002;20:2701-2712.

35. Baty BJ. Counseling by computer: Breast cancer risk and genetic testing. Am J Med Genet 1999;86:93-94.

36. McGee G. New media: Breast cancer counseling. JAMA 1999;281:1652.

37. Crowe JP. CD-ROM review: Counseling by computer: Breast cancer risk and genetic testing. J Womens Health 1999;8:25-26.

38. Dabney MK, Huelsman K. Software review: Counseling by computer: Breast cancer risk and genetic testing. Genet Test 2000;4:43-44.

39. McGee G. Beyond genetics: Putting the power of DNA to work in your life. New York: HarperCollins; 2003:96-99.

40. American Society of Clinical Oncology. Statement of the American Society of Clinical Oncology: Genetic testing for cancer susceptibility. J Clin Oncol 1996;14:17301736.

41. Davis TC, Long SW, Jackson RH, Mayeaux EJ, George RB, Murphy PW et al. Rapid estimate of adult literacy in medicine: a shortened screening instrument. Fam Med 1993;25:391-395.

42. Miles MB, Huberman AM. Qualitative data analysis: An expanded sourcebook, 2nd ed. Beverly Hills: Sage Publications, Inc; 1994.

43. Biesecker BB, Peters KF. Process studies in genetic counseling: peering into the black box. Am J Med Genet 2001;106:191-198.

44. Bernhardt BA, Biesecker BB, Mastromarino CL. Goals, benefits, and outcomes of genetic counseling: client and genetic counselor assessment. Am J Med Genet 2000; 94:189-197.

45. Fisher RJ. Social desirability bias and the validity of indirect questioning. J Consum Res 1993;20:303-315. 